\title{
Purinoceptors on Neuroglia
}

\author{
Alexei Verkhratsky • Oleg A. Krishtal • \\ Geoffrey Burnstock
}

Published online: 28 April 2009

(C) Humana Press Inc. 2009

\section{Erratum to: Mol Nuerobiol \\ DOI 10.1007/s12035-009-8063-2}

The original version of this article unfortunately contained a mistake. The spelling of Alexei Verkhratsky's name was incorrect. The corrected name was shown above.

The online version of the original article can be found at http://dx.doi. org/10.1007/s12035-009-8063-2.

A. Verkhratsky

School of Biological Sciences, The University of Manchester,

1.124 Stopford Building, Oxford Road,

Manchester M13 9PT, UK

A. Verkhratsky $(\bowtie)$

Institute of Experimental Medicine, ASCR,

Videnska 1083,

Prague 142 20, Czech Republic

e-mail: alex.verkhratsky@manchester.ac.uk

O. A. Krishtal

Bogomoletz Institute of Physiology,

Bogomoletz Str. 4,

Kiev, Ukraine

G. Burnstock

Autonomic Neuroscience Centre,

Royal Free and University College Medical School,

Rowland Hill Street,

London NW3 2PF, UK 